\title{
The role of DNA methylation in type I and 2 diabetes as related to endothelial cell dysfunction
}

\begin{abstract}
A major clinical problem associated with type 1 and 2 diabetes is the debilitating long term complications seen in this disease. This review will discuss 1) the role of epigenetics in type 1 and 2 diabetes, and 2) the dysfunction of endothelial cells in this disease, especially as related to blood vessel growth. While many tissues are affected in DM, pathologies associated with the endothelial cell are often central to these tissue problems. With the identification of epigenetic changes, (e.g. DNA methylation, histone modification, etc.) as processes associated with both DM and MM, investigators now have another potential target for investigation of the molecular mechanisms that may explain the persistent dysfunction seen in the many tissues affected in this disease.
\end{abstract}

Keywords: type 1 and 2 diabetes, epigenetics, DNA methylation, endothelial dysfunction in diabetes, alterations in blood vessel growth in diabetes
Volume I Issue I - 2015

\author{
Michael P Sarras,' Robert V Intine ${ }^{2}$ \\ 'Department of Cell Biology and Anatomy, Rosalind Franklin \\ University of Medicine and Science, USA \\ ${ }^{2}$ Department of Biomedical Sciences, Rosalind Franklin \\ University of Medicine and Science, USA
}

\begin{abstract}
Correspondence: Michael P Sarras, Department of Cell Biology and Anatomy, Rosalind Franklin University of Medicine and Science, USA, Tel 5204054739,
\end{abstract}

Email michael.sarras@rosalindfranklin.edu

Received: July 13, 2015 | Published: August 6, 2015
Abbreviations: DM, diabetes mellitus; MM, metabolic memory; EC, endothelial cell; BVG, blood vessel growth; HG, hyperglycemic; RNA, ribonucleic acid; DNA, deoxyribonucleic acid; $5 \mathrm{mC}$, 5- methylcytosine; AGE, advanced glycation end products; $\mathrm{CpG}$, cytosine-phosphate-guanine; H3K9/K14, histone acetylation groups; EPCs, endothelial progenitor cells

\section{Introduction}

Diabetes mellitus (DM) is projected to affect over 400 million worldwide by $2030 .{ }^{1}$ Diabetes mellitus is a disease of metabolic dysregulation ${ }^{2,3}$ resulting in microvascular and macrovascular complications. ${ }^{2,4}$ As such, the endothelial cell (EC) is a fundamental cell type targeted by the hyperglycemic (HG) episodes that occur in the disease. ${ }^{2,4-6}$ Endothelial cell dysfunction in DM is seen to take on different pathologies such as

\section{i. Altered compliance,}

ii. Acquired vascular flow abnormalities, ${ }^{8}$

iii. Altered blood vessel growth (BVG) \{through angiogenesis $5,9,10$ and neovascularisation $\}.,{ }^{6,1-14}$

Alterations in BVG affects a wide spectrum of organs/tissues in DM thereby causing systemic problems. ${ }^{9}$ In this regard, evidence from both the laboratory ${ }^{15-21}$ and large scale clinical trials ${ }^{4,22-35}$ has revealed that complications from the onset of hyperglycemia (such as impaired BVG) progress unimpeded via the phenomenon of "metabolic memory" (MM) even when glycemic control is pharmaceutically achieved. ${ }^{4,22-35}$ This applies to both type 1 and type 2 diabetes. The underlying molecular mechanisms of hyperglycemic complications and metabolic memory may include:

i. The involvement of excess reactive oxygen species,

ii. The involvement of advanced glycation end products (AGE),

iii. Alterations in tissue-wide gene expression patterns. ${ }^{2,3}$

However, the heritable nature of metabolic memory ${ }^{36,37}$ suggests a role for the epigenome. The epigenome is comprised of all chromatin modifying processes including DNA methylation and histone modifications allowing cells/organisms to quickly respond to changing environmental stimuli. ${ }^{38-40}$ These processes not only allow for quick adaptation but also confer the ability of the cell to "memorize" these encounters. ${ }^{38-40}$ The underlying molecular mechanism/s of MM has been examined via both animal model approaches and in vitro based studies. ${ }^{15-21}$ These studies establish that the initial hyperglycemia results in permanent aberrant gene expression in DM target tissues (e.g. cardiovascular system, kidney, retina, skin as related to wound healing, and impaired BVG such as seen in the wound healing process).

\section{Discussion}

\section{Potential Role of DNA methylation in metabolic memory of patients with type I and $\mathbf{2}$ diabetes}

While extensive epigenetic research has been conducted regarding histone modifications $\mathrm{s}^{41-50}$ and microRNA mechanisms $\mathrm{s}^{5,51-56}$ much less is known about the role of HG-induced persistent DNA methylation changes that occur in both type 1 and $2 \mathrm{DM}$. We have previously reported that hyperglycemia induces aberrant DNA methylation with concomitant altered gene expression patterns that correlate with persistent diabetic complications. ${ }^{19}$ The role of HG-induced DNA methylation changes within endothelial cells as related to persistent MM dysfunction remains unclear, particularly as related to alterations in BVG that is common to so many tissues targeted in DM. The role of epigenetics in diabetes is an important and expanding area of study. In this context it is important to note that the role of DNA methylation (as opposed to histone modifications) in DM is much less understood or studied. Epigenomes consist of all the chromatin modifications for a given cell type and are responsible for a cell's unique gene expression pattern. These chromosome modifications support cell differentiation and are dynamic throughout development. ${ }^{57-59}$ In addition, they are responsive to external stimuli, can be altered in disease, ${ }^{60}$ and are mitotically stably inherited. ${ }^{36,37}$ Epigenetic mechanisms include post-translational histone modifications, non-canonical histone variant inclusion in octomers, chromatin access changes through DNA methylation, and gene expression control through non-coding 
microRNAs. ${ }^{61-64}$ Altogether, these processes allow cells/organisms to quickly respond to changing environmental stimuli, ${ }^{38-40}$ and confer the ability for the cell to "memorize" these encounters once the stimulus is removed. ${ }^{38-40}$ Therefore, because gene expression changes resulting from epigenetic processes are stable in the absence of the signal that initiated them and are heritable through cell division, they have gained great interest as underlying molecular mechanisms of metabolic memory (MM). Significant advances have been made towards understanding the roles that histone modifications $\mathrm{s}^{41-50}$ and microRNAs ${ }^{5,51-56}$ play in the metabolic memory phenomenon; however, as indicated much less has been documented regarding the role of dynamic DNA Methylation. ${ }^{19,65-67}$ In this regard, DNA methylation occurs predominantly as 5 -methylcytosine $(5 \mathrm{mC})$; mostly in the context of $\mathrm{CpG}$ dinucleotides. In vertebrate genomes, these dinucleotides are clustered into regions (in order of decreasing $\mathrm{CpG}$ density) termed islands, shores, shelfs, and open seas. ${ }^{68,69}$ Multiple roles for DNA methylation including gene silencing, silencing of transposable elements, developmental regulation of transcription, cell cycle control, and differentiation have been documented. ${ }^{70-74}$ Historically, hypermethylation of $\mathrm{CpG}$ islands in promoter regions was thought to inhibit promoter activity by maintaining chromatin in a stably repressed state with alterations to this resulting in gene expression changes. However, more recent studies indicate that while this is correct for some loci; the majority of tissue specific expression and cancer-induced aberrant expression is governed by variations in the shore regions. ${ }^{69}$ Additionally, genome wide DNA methylation analyses have indicated that methylation in the "bodies" of active genes is significantly higher than those of inactive genes. ${ }^{75,76}$ This feature appears to be evolutionarily conserved and may function to suppress inappropriate transcription, regulate mRNA splicing, modulate elongation, and regulate tissue specific alternative promoter usage. ${ }^{77-81}$ Not unexpectedly, due to its critical role in gene expression, altered DNA methylation is associated with several human diseases including many cancers. ${ }^{82-86}$ Variations in "normal" DNA methylation are correlated with many aspects of DM including: susceptibility to $\mathrm{DM}^{87-89}$ insulin resistance, ${ }^{90}$ diabetes complication development, ${ }^{90}$ and early detection. ${ }^{91-93}$ Very recently, a comprehensive genomic DNA methylation profiling of type 2 diabetic islets revealed that $\mathrm{CpG}$ loci displayed a significant hypomethylation phenotype and may provide insight on diabetic islets and disease pathogenesis. ${ }^{94}$ The first report demonstrating a cause and effect relationship between hyperglycemia and altered DNA methylation documented that genomic hypomethylation was induced within the liver of type 1 diabetic rats as early as 2 weeks post hyperglycemia onset. ${ }^{67}$ Pirola et al. ${ }^{66}$ examined primary aortic endothelial cells exposed to high glucose (24hr) under in vitro conditions and performed a more comprehensive analysis of both histone acetylation and DNA Methylation. ${ }^{66}$ In this study they observed significant alterations in DNA methylation patterns and showed that induced methylation changes localized to regions within five kilobases of transcriptional start sites. They also observed broad changes to $\mathrm{H} 3 \mathrm{~K} 9 / \mathrm{K} 14$ acetylation and reported that regionalized hyper-acetylation correlated well with DNA hypomethylation and hyperglycemia-induced gene induction. However, these studies were limited to in vitro conditions did not examine results from a prolonged hyperglycemic state or the metabolic memory state.

\section{The central role of endothelial cells to the long term} complications seen in patients with type 1 and 2 diabetes

The role of endothelial cell (EC) dysfunction in the long term complications of diabetes is of profound importance and affects a broad array of tissues. ${ }^{9}$ This has been shown in the case of patients with long term DM as well as in a broad array of DM/MM animal models from rodent ${ }^{15,17}$ to Zebrafish. ${ }^{19,95}$ Endothelial dysfunction in $\mathrm{DM}$ is seen to take on different pathologies such as

i. Altered compliance, ${ }^{7}$

ii. Acquired vascular flow abnormalities, ${ }^{8}$

iii. Altered blood vessel growth (BVG) as related to the processes of angiogenesis $\mathrm{s}^{5,9,10}$ and neovascularization ${ }^{6,11-14}$ in the case of the adult human.

Angiogenesis in adult humans involves multiple stages $^{96}$ to include:

i. Tip activation,

ii. Sprouting,

iii. Anastomosis; each stage has its own set of regulatory genes. ${ }^{5,96}$

All of these angiogenic stages are affected in the diabetic state. ${ }^{5,96}$ Neovascularization, which was once thought to only occur during embryonic development, has now been shown in mammals to also contribute to BVG in the adult. ${ }^{97}$ This occurs via endothelial progenitor cells (EPCs) which mainly arise from the bone marrow but are also seen in the peripheral blood. ${ }^{98}$ These EPCs differentiate to endothelial cells and seed to blood vessels; thereby contributing to the process of blood vessel growth in the adult mammal (e.g. human). This has potential therapeutic value because of the EPC's ability to promote blood vessel growth/repair. Angiogenesis and neovascularization utilize a "common gene kit" of regulatory genes. ${ }^{5,96,97}$ In the context of diabetes, EPCs from DM patients have been found to be affected by the disease. For example, EPC numbers are reduced in the diabetic patient, ${ }^{99}$ have some alterations in proliferation, adhesion, and incorporation into vascular structures. ${ }^{100}$ Additionally, EPCs obtained from diabetic subjects have been shown to have DNA methylation changes in the promoter regions of key blood vessel growth regulator genes. ${ }^{101}$ Taken in total, these studies indicate that analysis of DNA methylation changes in the endothelial cells of the diabetic state via analysis of EPCs may lead to a better understanding of the underlying mechanisms of the long term complications of type 1 and 2 diabetes. To be complete, it should be noted that in regard to the dysfunction of endothelial cells in diabetes, the role of miRNAs and histone epigenetic modifications are also of critical importance. As recently reviewed by Prattichizzo et al. ${ }^{102}$

i. Circulating miRNAs such as miR-126 in type $2 \mathrm{DM}$ patients have been linked to inflammatory pathways in the disease and

ii. Gucose-mediated changes in the transcription and activation of NF-kB in endothelial cells of DM patients is tied to a) recruitment of histone methyltransferase Set7 with increased monomethlylation of H3K9 (lysine 4 of histone 3), b) increased recruitment of histone demethylase LSD1 with reduced $\mathrm{H} 3 \mathrm{~K} 9$ methylation, c) histone acetyltransferase (HAT)-mediated histone H3K9 hyperacetylation. These a just a few examples of the many roles miRNAs and histone epigenetic changes have in the dysfunction of endothelial cells in diabetes. Additionally, a large body of literature also ties these pathological epigenetic processes to cancer ${ }^{103,104}$ which also involves abnormalities in cell proliferation as seen in diabetes.

\section{Conclusion}

A major clinical problem associated with type 1 and 2 diabetes is the 
debilitating long term complications seen in this disease. While many tissues are affected in DM, pathologies associated with the endothelial cell are often central to these tissue problems. With the identification of epigenetic changes, (e.g. tissue-specific DNA methylation, direct DNA methylation within pancreatic b-cells, ${ }^{105,106}$ histone modification, etc.) as processes associated with both DM and MM, investigators now have another potential target for investigation of the molecular mechanisms that may explain the persistent dysfunction seen in the many tissues affected in this disease. The combination of epigenetic analysis and endothelial cell function could lead to the identification of molecular targets for therapeutic intervention for the treatment and possible prevention of secondary complications of this metabolic disease. A general summary of the events associated with changes in DNA methylation patterns in diabetes is depicted in the article (Figure $1)$.

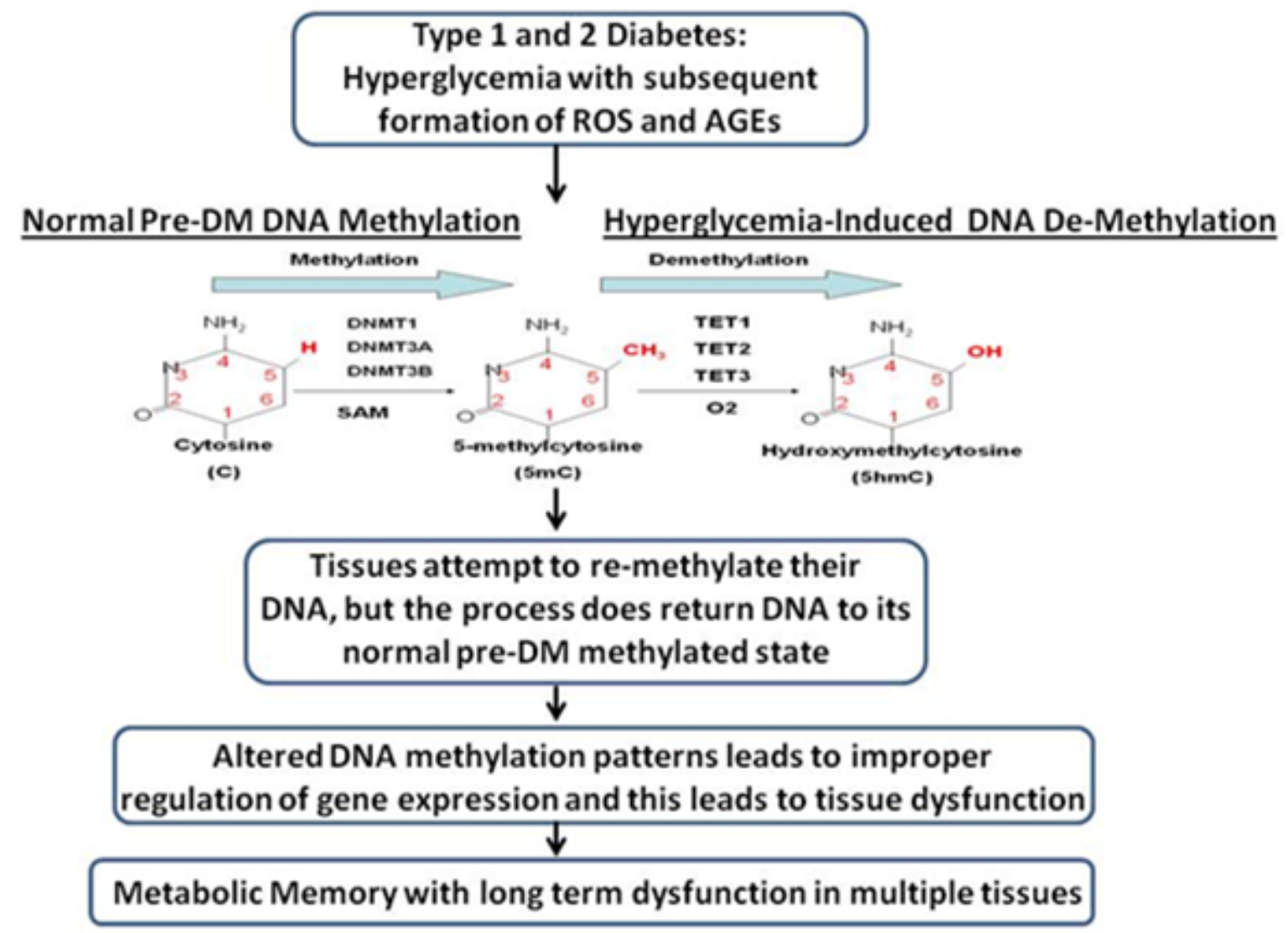

Figure I Events in type I and type 2 diabetes that are associated with DNA methylation changes and subsequent long-term tissue dysfunction.

\section{Acknowledgements}

None.

\section{Conflict of interest}

Author declares that there is no conflict of interest.

\section{References}

1. Shaw JE, Sicree RA, Zimmet PZ. Global estimates of the prevalence of diabetes for 2010 and 2030. Diabetes Res Clin Pract. 2010;87(1):4-14.

2. Brownlee M. The pathobiology of diabetic complications: a unifying mechanism. Diabetes. 2005;54(6):1615-1625.

3. Baynes JW. Role of oxidative stress in development of complications in diabetes. Diabetes. 1991;40(4):405-412.

4. Costa PZ, Soares R. Neovascularization in diabetes and its complications Unraveling the angiogenic paradox. Life Sci. 2013;92(22):1037-1045.

5. Carmeliet P. Angiogenesis in life, disease and medicine. Nature. 2005;438(7070):932-936.
6. Menegazzo L, Albiero M, Avogaro A, et al. Endothelial progenitor cells in diabetes mellitus. Biofactors. 2012;38(3):194-202.

7. Manolis AJ, Iraklianou S, Pittaras A, et al. Arterial compliance changes in diabetic normotensive patients after angiotensin-converting enzyme inhibition therapy. Am J Hypertens. 2005;18(1):18-22.

8. van Golen LW, IJzerman RG, Huisman MC, et al. Cerebral blood flow and glucose metabolism in appetite-related brain regions in type 1 diabetic patients after treatment with insulin detemir and NPH insulin: a randomized controlled crossover trial. Diabetes Care. 2013;36(12):4050-4056.

9. Inzucchi S, Majumdar S. Glycemic Targets: What is the Evidence? Med Clin North Am. 2015;99(1):47-67.

10. Kononenkov VI, Klimontov VV, Kuznetsova IV. [Impaired angiogenesis and lymphangiogenesis in diabetes mellitus]. Arkh Patol. 2014;76(2):55-59.

11. Fadini GP, Ferraro F, Quaini F, et al. Concise review: diabetes, the bone marrow niche, and impaired vascular regeneration. Stem Cells Transl Med. 2014;3(8):949-957. 
12. Fadini GP, Miorin M, Facco M, et al. Circulating endothelial progenitor cells are reduced in peripheral vascular complications of type 2 diabetes mellitus. J Am Coll Cardiol. 2005;45(9):1449-1457.

13. van AJ, Moser J, Lexis CP, et al. Type 2 diabetes mellitus is associated with an imbalance in circulating endothelial and smooth muscle progenitor cell numbers. Diabetologia. 2012;55(9):2501-2512.

14. Kim KA, Shin YJ, Akram M, et al. High glucose condition induces autophagy in endothelial progenitor cells contributing to angiogenic impairment. Biol Pharm Bull. 2014;37(7):1248-1252.

15. Roy S, Sala R, Cagliero E, et al. Overexpression of fibronectin induced by diabetes or high glucose: phenomenon with a memory. Proc Natl Acad Sci USA. 1990;87(1):404-408.

16. Kowluru RA, Chakrabarti S, Chen S. Re-institution of good metabolic control in diabetic rats and activation of caspase-3 and nuclear transcriptional factor (NF-kappaB) in the retina. Acta Diabetol. 2004;41(4):194-199.

17. Hammes HP, Klinzing I, Wiegand S, et al. Islet transplantation inhibits diabetic retinopathy in the sucrose-fed diabetic Cohen rat. Invest Ophthalmol Vis Sci. 1993;34(6):2092-2096.

18. Engerman RL, Kern TS. Progression of incipient diabetic retinopathy during good glycemic control. Diabetes. 1987;36(7):808-812.

19. Olsen AS, Sarras MP, Leontovich A, et al. Heritable Transmission of Diabetic Metabolic Memory in Zebrafish Correlates With and Aberrant Gene Expression. Diabetes. 2012;61(2):485-491.

20. Kowluru RA. Effect of reinstitution of good glycemic control on retinal oxidative stress and nitrative stress in diabetic rats. Diabetes. 2003;52(3):818-823.

21. Li SL, Reddy MA, Cai Q, et al. Enhanced proatherogenic responses in macrophages and vascular smooth muscle cells derived from diabetic db/db mice. Diabetes. 2006;55(9):2611-2619.

22. Riddle MC. Effects of intensive glucose lowering in the management of patients with type 2 diabetes mellitus in the Action to Control Cardiovascular Risk in Diabetes (ACCORD) trial. Circulation. 2010;122(8):844-846.

23. Skyler JS, Bergenstal R, Bonow RO, et al. Intensive glycemic control and the prevention of cardiovascular events: implications of the ACCORD, ADVANCE, and VA diabetes trials: a position statement of the American Diabetes Association and a scientific statement of the American College of Cardiology Foundation and the American Heart Association. Diabetes Care. 2009;32(1):187-192.

24. Duckworth WC, McCarren M, Abraira C, et al. Glucose control and cardiovascular complications: the VA Diabetes Trial. Diabetes Care. 2001;24(5):942-945

25. Ismail-Beigi $\mathrm{F}$, Craven T, Banerji MA, et al. Effect of intensive treatment of hyperglycaemia on microvascular outcomes in type 2 diabetes: an analysis of the ACCORD randomised trial. Lancet. 2010;376(9739):419-430.

26. Gaede P, Valentine WJ, Palmer AJ, et al. Cost-effectiveness of intensified versus conventional multifactorial intervention in type 2 diabetes: results and projections from the Steno-2 study. Diabetes Care. 2008;31(8):1510-1515.

27. Gaede PH, Jepsen PV, Larsen JNB, et al. [The Steno-2 study. Intensive multifactorial intervention reduces the occurrence of cardiovascular disease in patients with type 2 diabetes]. Ugeskr Laeger. 2003;165(26):2658-2661.

28. Turner RC, Cull CA, Frighi V, et al. Glycemic control with diet, sulfonylurea, metformin, or insulin in patients with type 2 diabetes mellitus: progressive requirement for multiple therapies (UKPDS 49). UK Prospective Diabetes Study (UKPDS) Group. JAMA. $1999 \cdot 281(21) \cdot 2005-2012$.
29. Retinopathy and nephropathy in patients with type 1 diabetes four years after a trial of intensive therapy. The Diabetes Control and Complications TrialEpidemiology of Diabetes Interventions and Complications Research Group. N Engl J Med. 2000;342(6):381-389.

30. Intine RV, Sarras MP. Metabolic memory and chronic diabetes complications: potential role for epigenetic mechanisms. Curr Diab Rep. 2012;12(5):551-559.

31. The effect of intensive treatment of diabetes on the development and progression of long-term complications in insulin-dependent diabetes mellitus. The Diabetes Control and Complications Trial Research Group. N Engl J Med. 1993;329(14):977-986.

32. Sustained effect of intensive treatment of type 1 diabetes mellitus on development and progression of diabetic nephropathy: the Epidemiology of Diabetes Interventions and Complications (EDIC) study. JAMA. 2003;290(16):2159-2167.

33. Holman RR, Paul SK, Bethel MA, et al. 10-year follow-up of intensive glucose control in type 2 diabetes. $N$ Engl $J$ Med 2008;359(15):1577-1589.

34. Ceriello A, Ihnat MA, Thorpe JE. Clinical review 2: The "metabolic memory": is more than just tight glucose control necessary to prevent diabetic complications? J Clin Endocrinol Metab. 2009;94(2):410-415.

35. Ihnat MA, Thorpe JE, Kamat CD, et al. Reactive oxygen species mediate a cellular 'memory' of high glucose stress signalling. Diabetologia. 2007;50(7):1523-1531

36. Morgan DK, Whitelaw E. The case for transgenerational epigenetic inheritance in humans. Mamm Genome. 2008;19(6):394-397.

37. Dolinoy DC, Jirtle RL. Environmental epigenomics in human health and disease. Environ Mol Mutagen. 2008;49(1):4-8.

38. Gluckman PD, Hanson MA, Beedle AS. Non-genomic transgenerational inheritance of disease risk. Bioessays. 2007;29(2):145-154.

39. Whitelaw NC, Whitelaw E. Transgenerational epigenetic inheritance in health and disease. Curr Opin Genet Dev. 2008;18(3):273-279.

40. Bjornsson HT, Fallin MD, Feinberg AP. An integrated epigenetic and genetic approach to common human disease. Trends Genet. 2004;20(8):350-358.

41. Rando OJ. Combinatorial complexity in chromatin structure and function: revisiting the histone code. Curr Opin Genet Dev. 2012;22(2):148-155.

42. Zhong Q, Kowluru RA. Epigenetic changes in mitochondrial superoxide dismutase in the retina and the development of diabetic retinopathy Diabetes. 2011;60(4):1304-1313.

43. Zhong Q, Kowluru RA. Role of histone acetylation in the development of diabetic retinopathy and the metabolic memory phenomenon. $J$ Cell Biochem. 2010;110(6):1306-1313.

44. Brasacchio D, Okabe J, Tikellis C, et al. Hyperglycemia induces a dynamic cooperativity of histone methylase and demethylase enzymes associated with gene-activating epigenetic marks that coexist on the lysine tail. Diabetes. 2009;58(5):1229-1236.

45. El-Osta A, Brasacchio D, Yao D, et al. Transient high glucose causes persistent epigenetic changes and altered gene expression during subsequent normoglycemia. $J$ Exp Med. 2008;205(10):2409-2417.

46. Miao F, Smith DD, Zhang L, et al. Lymphocytes from patients with type 1 diabetes display a distinct profile of chromatin histone H3 lysine 9 dimethylation: an epigenetic study in diabetes. Diabetes. 2008;57(12):3189-3198.

47. Miao F, Wu X, Zhang L, et al. Genome-wide analysis of histone lysine methylation variations caused by diabetic conditions in human monocytes. J Biol Chem. 2007;282(18):13854-13863. 
48. Miao F, Gonzalo IG, Lanting L, et al. In vivo chromatin remodeling events leading to inflammatory gene transcription under diabetic conditions. J Biol Chem. 2004;279(17):18091-18097.

49. Li Y, Reddy MA, Miao F, et al. Role of the histone H3 lysine 4 methyltransferase, SET7/9, in the regulation of NF-kappaB-dependent inflammatory genes. Relevance to diabetes and inflammation. $J$ Biol Chem. 2008;283(39):26771-26781.

50. Yu J, Auwerx J. Protein deacetylation by SIRT1: an emerging key posttranslational modification in metabolic regulation. Pharmacol Res. 2010;62(1):35-41.

51. Putta S, Lanting L, Sun G, et al. Inhibiting microRNA-192 ameliorates renal fibrosis in diabetic nephropathy. J Am Soc Nephrol. 2012;23(3):458-469.

52. Wang B, Koh $\mathrm{P}$, Winbanks $\mathrm{C}$, et al. miR-200a Prevents renal fibrogenesis through repression of TGF- $\beta 2$ expression. Diabetes. 2011;60(1):280-287.

53. Kato M, Zhang J, Wang M, et al. MicroRNA-192 in diabetic kidney glomeruli and its function in TGF-beta-induced collagen expression via inhibition of E-box repressors. Proc Natl Acad Sci $U S A$ 2007;104(9):3432-3437.

54. McArthur K, Feng B, Wu Y, et al. MicroRNA-200b regulates vascular endothelial growth factor-mediated alterations in diabetic retinopathy. Diabetes. 2011;60(4):1314-1323.

55. Feng B, Chen S, McArthur K, et al. miR-146a-Mediated extracellular matrix protein production in chronic diabetes complications. Diabetes. 2011;60(11):2975-2984.

56. Ruan Q, Wang T, Kameswaran V, et al. The microRNA-21-PDCD4 axis prevents type 1 diabetes by blocking pancreatic beta cell death. Proc Natl Acad Sci U S A. 2011;108(29):12030-12035.

57. Jirtle RL, Sander M, Barrett JC. Genomic imprinting and environmental disease susceptibility. Environ Health Perspect. 2000;108(3):271-278.

58. Jaenisch R, Bird A, Jirtle RL, et al. Epigenetic regulation of gene expression: how the genome integrates intrinsic and environmental signals. Nat Genet. 2000;33:245-254.

59. Ho L, Crabtree GR. Chromatin remodelling during development. Nature. 2010;463(7280):474-484

60. Heerboth S, Lapinska K, Snyder N, et al. Use of epigenetic drugs in disease: an overview. Genet Epigenet. 2014;6:9-19.

61. Kouzarides T. Chromatin modifications and their function. Cell. 2007;128(4):693-705.

62. Mosammaparast N, Shi Y. Reversal of histone methylation: biochemical and molecular mechanisms of histone demethylases. Annu Rev Biochem. 2010;79:155-179.

63. Bogdanovic O, Veenstra GJ. DNA methylation and methyl-CpG binding proteins: developmental requirements and function. Chromosoma. 2009;118(5):549-565.

64. Blomen VA, Boonstra J. Stable transmission of reversible modifications: maintenance of epigenetic information through the cell cycle. Cell Mol Life Sci. 2010;68(1):27-44.

65. Williams KT, Schalinske KL. Tissue-specific alterations of methyl group metabolism with DNA hypermethylation in the Zucker (type 2) diabetic fatty rat. Diabetes Metab Res Rev. 2012;28(2):123-131.

66. Pirola L, Balcerczyk A, Tothill RW, et al. Genome-wide analysis distinguishes hyperglycemia regulated epigenetic signatures of primary vascular cells. Genome Res. 2011;21(10):1601-1615.

67. Williams KT, Garrow TA, Schalinske KL. Type I diabetes leads to tissue-specific DNA hypomethylation in male rats. $J$ Nutr. 2008;138(11):2064-2069
68. Sandoval J, Heyn H, Moran S, et al. Validation of a DNA methylation microarray for $450,000 \mathrm{CpG}$ sites in the human genome. Epigenetics. 2011;6(6):692-702.

69. Irizarry RA, Ladd-Acosta C, Wen B, et al. The human colon cancer methylome shows similar hypo- and hypermethylation at conserved tissue-specific CpG island shores. Nat Genet. 2009;41(2):178-186.

70. Chen T, Hevi S, Gay Fdr, et al. Complete inactivation of DNMT1 leads to mitotic catastrophe in human cancer cells. Nat Genet. 2007;39(3):391-396.

71. Li E, Bestor TH, Jaenisch R. Targeted mutation of the DNA methyltransferase gene results in embryonic lethality. Cell. 1992;69(6):915-926.

72. Zilberman D, Gehring M, Tran RK, et al. Genome-wide analysis of Arabidopsis thaliana DNA methylation uncovers an interdependence between methylation and transcription. Nat Genet. 2007;39(1):61-69.

73. Reik W, Dean W, Walter J. Epigenetic reprogramming in mammalian development. Science. 2001;293(5532):1089-1093.

74. Walsh CP, Bestor TH. Cytosine methylation and mammalian development. Genes Dev. 1999;13(1):26-34.

75. Ball MP, Li JB, Gao Y, et al. Targeted and genome-scale strategies reveal gene-body methylation signatures in human cells. Nat Biotechnol. 2009;27(4):361-368.

76. Lister R, Pelizzola M, Dowen RH, et al. Human DNA methylomes at base resolution show widespread epigenomic differences. Nature. 2009;462(7271):315-322.

77. Suzuki MM, Bird A. DNA methylation landscapes: provocative insights from epigenomics. Nat Rev Genet. 2008;9(6):465-476.

78. Lorincz MC, Dickerson DR, Schmitt $\mathrm{M}$, et al. Intragenic DNA methylation alters chromatin structure and elongation efficiency in mammalian cells. Nat Struct Mol Biol. 2004;11(11):1068-1075.

79. Maunakea AK, Nagarajan RP, Bilenky M, et al. Conserved role of intragenic DNA methylation in regulating alternative promoters. Nature. 2010;466(7303):253-257.

80. Suzuki MM, Kerr ARW, De Sousa D, et al. CpG methylation is targeted to transcription units in an invertebrate genome. Genome Res. 2007;17(5):625-631.

81. Zemach A, McDaniel IE, Silva P, et al. Genome-wide evolutionary analysis of eukaryotic DNA methylation. Science. 2010;328(5980):916-919.

82. Mastroeni D, Grover A, Delvaux E, et al. Epigenetic mechanisms in Alzheimer's disease. Neurobiol Aging. 2011;32(7):1161-1180.

83. Casaccia-Bonnefil P, Pandozy G, Mastronardi F. Evaluating epigenetic landmarks in the brain of multiple sclerosis patients: a contribution to the current debate on disease pathogenesis. Prog Neurobiol. 2008;86(4):368-378

84. Watanabe Y, Maekawa M. Methylation of DNA in cancer. Adv Clin Chem. 2010;52:145-167.

85. Goll MG, Bestor TH. Eukaryotic cytosine methyltransferases. Annu Rev Biochem. 2005;74:481-514.

86. Laird PW. Cancer epigenetics. Hum Mol Genet. 2005;1:R65-R76.

87. Caramori ML, Kim Y, Moore JH, et al. Gene expression differences in skin fibroblasts in identical twins discordant for type 1 diabetes. Diabetes. 2012;61(3):739-744.

88. Ling C, Del Guerra S, Lupi R, et al. Epigenetic regulation of PPARGC1A in human type 2 diabetic islets and effect on insulin secretion. Diabetologia. 2008;51(4):615-622.

89. Morgan HD, Sutherland HG, Martin DI, et al. Epigenetic inheritance at the agouti locus in the mouse. Nat Genet. 1999;23(3):314-318. 
90. Zhao J, Goldberg J, Bremner JD, et al. Global DNA methylation is associated with insulin resistance: a monozygotic twin study. Diabetes. 2012;61(2):542-546.

91. Rakyan VK, Beyan H, Down TA, et al. Identification of type 1 diabetesassociated DNA methylation variable positions that precede disease diagnosis. PLoS Genet. 2011;7(9):e1002300.

92. Toperoff G, Aran D, Kark JD, et al. Genome-wide survey reveals predisposing diabetes type 2-related DNA methylation variations in human peripheral blood. Hum Mol Genet. 2012;21(2):371-383.

93. Akirav EM, Lebastchi J, Galvan EM, et al. Detection of $\beta$ cell death in diabetes using differentially methylated circulating DNA. Proc Natl Acad Sci U S A. 2011;108(47):19018-19023.

94. Volkmar M, Dedeurwaerder S, Cunha DA, et al. DNA methylation profiling identifies epigenetic dysregulation in pancreatic islets from type 2 diabetic patients. EMBO J. 2012;31(6):1405-1426.

95. Capiotti KM, Antonioli R, Kist LW, et al. Persistent impaired glucose metabolism in a zebrafish hyperglycemia model. Comp Biochem Physiol B Biochem Mol Biol. 2014;171:58-65.

96. Siekmann AF, Affolter M, Belting HG. The tip cell concept 10 years after: new players tune in for a common theme. Exp Cell Res. 2013;319(9):1255-1263.

97. Luttun A, Carmeliet G, Carmeliet P. Vascular progenitors: from biology to treatment. Trends Cardiovasc Med. 2002;12(2):88-96.

98. Goerke SM, Obermeyer J, Plaha J, et al. Endothelial progenitor cells from peripheral blood support bone regeneration by provoking an angiogenic response. Microvasc Res. 2014;98:40-47.
99. Antonio N, Fernandes R, Soares A, et al. Reduced levels of circulating endothelial progenitor cells in acute myocardial infarction patients with diabetes or pre-diabetes: accompanying the glycemic continuum. Cardiovasc Diabetol. 2014;13:101.

100. Tepper OM, Galiano RD, Capla JM, et al. Human endothelial progenitor cells from type II diabetics exhibit impaired proliferation, adhesion, and incorporation into vascular structures. Circulation. 2002;106(22):2781-2786

101. Young-sup Yoon. Reprogramming diabetic stem or progenitor cells for treating diabetic complications. 2013.

102. Prattichizzo F, Giuliani A, Ceka A, et al. Epigenetic mechanisms of endothelial dysfunction in type 2 diabetes. Clin Epigenetics. 2015;7(1):56

103. Hitchler MJ, Domann FE. Redox regulation of the epigenetic landscape in cancer: a role for metabolic reprogramming in remodeling the epigenome. Free Radic Biol Med. 2012;53(11):2178-2187.

104. Cyr AR, Hitchler MJ, Domann FE. Regulation of SOD2 in cancer by histone modifications and $\mathrm{CpG}$ methylation: closing the loop between redox biology and epigenetics. Antioxid Redox Signal. 2013;18(15):1946-1955.

105. Dhawan S, Tschen SI, Zeng C, et al. DNA methylation directs functional maturation of pancreatic $\beta$ cells. J Clin Invest. 2015;125(7):2851-2860.

106. Schuit F. Epigenetic programming of glucose-regulated insulin release. J Clin Invest. 2015;125(7):2565-2568. 